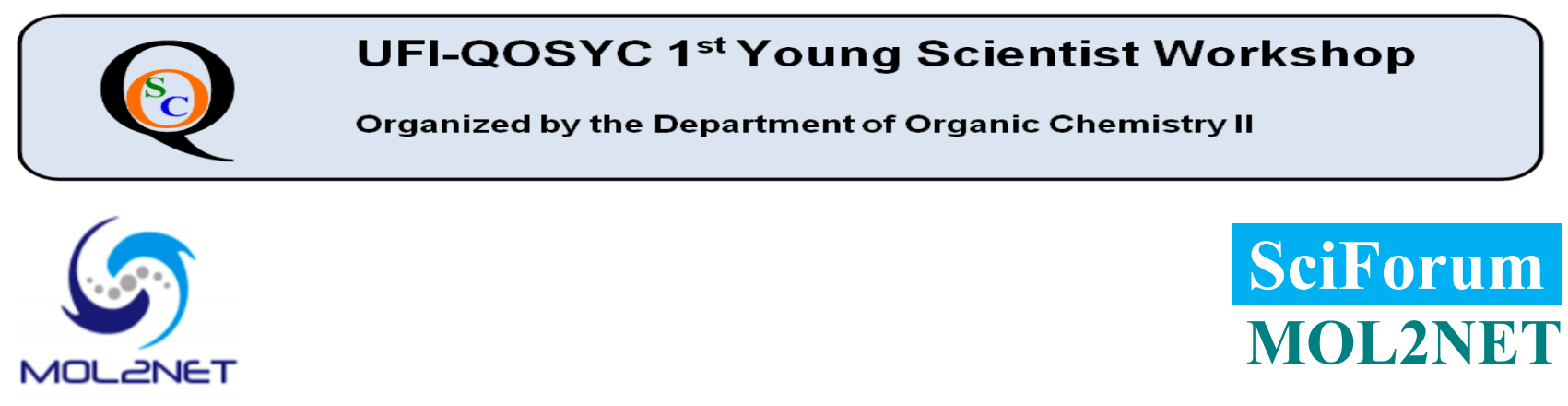

\title{
Searching for new applications of the hypervalent iodine reagents in the construction of nitrogen containing compounds
}

\section{Izaskun Dávila Rodríguez}

\section{Departamento de Química Orgánica II, Facultad de Ciencia y Tecnología Universidad del País Vasco - Euskal Herriko Unibertsitatea \\ izas-15@hotmail.com}

The search for novel applications of the hypervalent iodine reagents in organic synthesis has witnessed a huge development in the last years due to the fact that most of them shows activity in the presence of almost all types of functional groups. ${ }^{1}$ Their high stability and ease of use make these reagents ideal candidates to be included in many synthetic designs. The two main aspects of the reactivity of this kind of reagents are (i) the high electrophility at the iodine atom, and (ii) the extremely high ability of iodobenzene (the resulting by-product of several of the most commonly used hypervalent iodine chemicals) to act as a "super-leaving group". Continuing our interest in this field, we are facing at the moment a new challenge. ${ }^{2}$ The ability of some I(III) reagents, such as diaryliodonium salts 4, to transfer one of their groups to the nucleophilic position of different substrates ${ }^{3}$ has been employed, for example, in the metal-free arylation of malonates $\mathbf{1}{ }^{4}$ The required conditions to accomplish this task (enolate formation under basic conditions) are similar to the ones required to perform a subsequent construction of a barbituric acid of type $\mathbf{3}$ in the presence of ureas $\mathbf{5}^{5}$ In other words, it is the aim of this project to perform the two-step synthesis of 5-aryl substituted barbituric acids 3 in a one-pot procedure (without isolation of $\mathbf{2}$ ) or even in a multicomponent approach (Scheme 1).

Scheme 1. Two different strategies directed to the preparation of 5-arylsubstituted barbituric acids 3 .

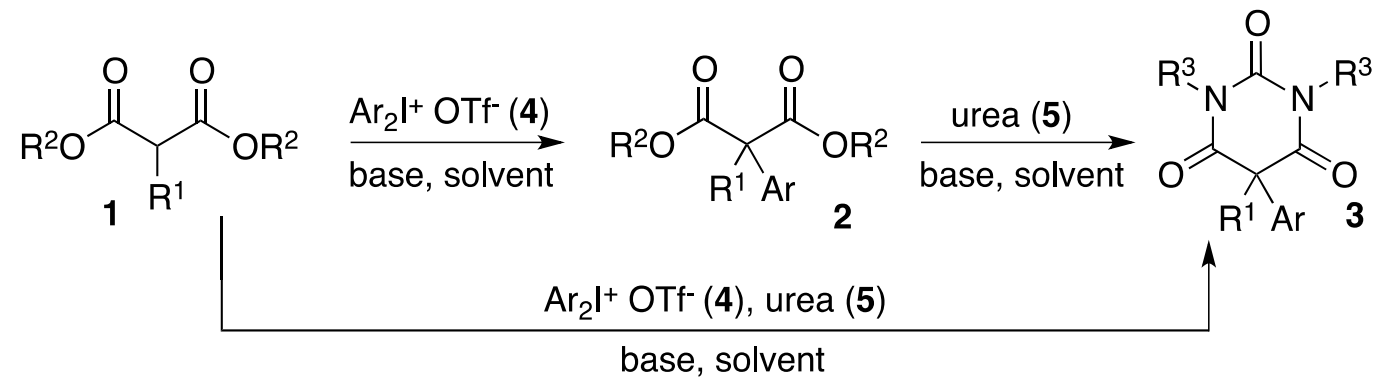

\footnotetext{
${ }^{1}$ See, for example, (a) Zhdankin, V. V.; Stang, P. J. Chem. Rev. 2008, 108, 5299. (b) Varvoglis, A. The Organic Chemistry of Polycoordinated Iodine, VCH, Weinheim, 1992. (c) Hypervalent Iodine Chemistry, in Top. Curr. Chem. 224, Wirth, T. Ed., Springer, Berlin, 2003. (d) Pouységu, L.; Deffieux, D.; Quideau, S. Tetrahedron 2010, 66, 2235. (e) Varvoglis, A. Tetrahedron 1997, 53, 1179.

${ }^{2}$ For a review of a summary of our contributions, see: Tellitu, I.; Domínguez, E. Synlett 2012, 2165, and references cited therein.

${ }^{3}$ Merritt, E. A.; Olofsson, B. Angew. Chem. Int. Ed. 2009, 48, 9052.

${ }^{4}$ Oh, C. H.; Kim, J. S.; Jung, H. H. J. Org. Chem. 1999, 64, 1338.

${ }^{5}$ Dickey, J. B.; Gray, A. R. Org. Synth. 1943, Coll. Vol. 2, 60.
} 